\title{
APRENDIZADO DE LÍNGUA - INCIDENTAL LEARNING E O DESENVOLVIMENTO DA BILINGUALIDADE E DO LETRAMENTO DO APRENDIZ
}

\author{
Márjori Correa MENDES \\ Programa de Pós-Graduação em Linguística - Universidade Federal de Juiz de Fora \\ Ana Claudia Peters SALGADO \\ Programa de Pós-Graduação em Linguística - Universidade Federal de Juiz de Fora
}

RESUMO: O mundo em que vivemos hoje é caracterizado pela superdiversidade (VERTOVEC, 2006), o que implica diretamente na maneira pela qual nos comunicamos e recebemos informação, além de influenciar as diferentes formas de contatos linguísticos dentro e fora de sala de aula. Nesse viés, este trabalho busca discutir como as crianças desenvolvem suas bilingualidades (SALGADO \& DIAS, 2010) a partir de informações disponíveis em seu entorno e como esse processo contribui, também, para a construção de seus letramentos (FREIRE, 1991; STREET, 1984; 2003), indo ao encontro do que García (2009) entende como educação bilíngue. Para tanto, serão analisadas algumas notas de campo produzidas durante as observações de aulas em uma instituição particular de ensino de língua estrangeira na cidade de Juiz de Fora/MG, parte de um projeto de iniciação científica desenvolvido entre os anos de 2009 e 2010. O que podemos concluir a partir dos dados coletados é que a criança aprende muito de forma incidental. Sendo assim, quanto maior for a quantidade e qualidade de input linguístico disponível no contexto escolar, maiores serão as possibilidades de as crianças aprenderem na forma de incidental learning (KERKA, 2000; VAZQUEZ, 2014; GRIM-FEINBERG, 2015) e mais consistente e independente será sua produção. Para que isso ocorra, no entanto, é necessário que haja a disponibilidade de uma grande e variada quantidade desse input para essa criança, através de um professor com uma formação criteriosa e de um contexto que possibilite diferentes oportunidades para o aprendiz aprender de acordo com suas especificidades e preferências.

Palavras chave: Aprendizado incidental; Bilingualidade; Educação Bilíngue.

ABSTRACT: Nowadays the world is characterized by its superdiversity (VERTOVEC, 2006), what influences directly on the way we communicate and receive information. Furthermore, it influences the different means of linguistic contact within and outside the classroom. Thus, this paper aims to discuss how children develop their bilinguality (SALGADO \& DIAS, 2010) through the information available around them and how such process contributes, also, to the development of their literacy skills (FREIRE, 1991; STREET, 1984, 2003), connecting it to what García (2009) understands as Bilingual Education. For doing so, some expanded notes produced during class observations in a private institute of foreign language teaching in the city of Juiz de Fora/MG will be analyzed. They are part of a project developed between 2009 and 2011. We can conclude, based on the data that children learn much more incidentally than we can suppose. In this sense, the higher the quality and amount of linguistic input available in the school context, the bigger are the chances of those learners learn something in the form of incidental learning (KERKA, 2000; VAZQUEZ et al, 2014; GRIM-FEINBERG, 2015). The notes also show that their production tend to be more consistent and independent. It is necessary, though, to have a great and diverse amount of linguistic input available for the children, presented by a teacher with qualified formation and a context that allows and understands different opportunities for the learners to learn according to their peculiarities and interests.

Key-words: Incidental Learning; Bilinguality; Bilingual Education. 


\section{Introdução}

O mundo atual se caracteriza pelo globalismo (KUMARAVADIVELU, 2012), isto é, é um mundo no qual as relações humanas ocorrem em escala global e em uma intensidade sem precedentes, através dos mais diversos suportes. Essa nova configuração tem, por certo, influenciado fortemente a maneira pela qual nos comunicamos e potencializou as oportunidades de contato linguístico para além das fronteiras físicas. Face a toda essa nova dinâmica que estamos vivenciando, faz-se necessário repensar como a educação linguística tem ocorrido dentro do contexto escolar, a fim de alinhá-la às novas demandas que se apresentam. Sendo assim, muito mais do que tornar os aprendizes falantes "proficientes" em uma língua, é preciso torna-los aptos a agir em seus contextos interacionais a partir de suas práticas discursivas. Dessa forma, o objetivo principal deste trabalho é apresentar uma proposta de educação linguística que fomente a agentividade linguística dos aprendizes dentro de seus universos interacionais. Para tanto, discutiremos a redefinição de alguns conceitos importantes, como a noção do que seja língua, o entendimento do que seja bilinguismo e de quem seria considerado bilíngue e a criação de espaços dentro de sala de aula. Feito isso, apresentaremos o conceito de aprendizado incidental e trataremos de sua influência no desenvolvimento da bilingualidade e do letramento de crianças aprendizes ${ }^{1}$ de língua estrangeira inseridas em um contexto de educação bilíngue.

\section{Definições e abordagens}

A partir dessa nova configuração, o primeiro aspecto que merece atenção é a própria definição do que seja língua. Dentro de uma sociedade onde as fronteiras têm se tornado cada vez mais fluidas, parece-me um pouco arriscado continuar pensando língua como um sistema de regras isolado e, de certa forma, estático, distante da realidade social de seus falantes. Torna-se imperativo, então, pensar a língua para além do signo linguístico. Como já aponta García (2009), os processos de globalização ${ }^{2}$ já tornam evidente que as línguas não pertencem a determinados estados e não se manifestam da mesma maneira em todos os contextos (2009, p. 25). Dessa forma, é importante considerar e refletir com quem, como e porque uma língua está sendo utilizada dentro de determinada interação.

Autores como Juffermans (2010), Canagarajah (2010), García (2009) e Shohamy (2006) já discutem a necessidade de se levar em consideração o contexto interacional para, então, entender a variedade e as práticas linguísticas dos indivíduos ali inseridos. Eles vão classificar essas práticas linguísticas como languaging, termo traduzido aqui como "linguação". Como o próprio nome sugere, a linguação pressupõe ação do indivíduo que faz uso de determinada prática discursiva dentro da interação da qual participa. Ao se apropriar de tal prática e lançar mão de seu uso, o falante está, também, se posicionando dentro da relação que ali se estabelece, demarcando os lugares aos quais pertence, ou não, através de seu discurso (MALINOVSKI, 2016) ${ }^{3}$. Ao ato de "linguar" bilíngue os autores dão o nome de translanguaging, traduzido aqui como "translinguação".

Esse novo entendimento do que seja língua acaba por influenciar diretamente na maneira como enxergamos os aprendizes envolvidos nos processos de ensino-aprendizagem de uma língua. Uma consequência importante dessa mudança paradigmática é a

\footnotetext{
${ }^{1}$ A faixa-etária das crianças em questão varia entre 3 e 8 anos de idade.

2 Quando me refiro a globalização dentro deste trabalho faço referência à definição apresentada por Kumaravadivelu (2006).

${ }^{3}$ Acting on Linguistic Landscape: Performativity, Translation, and Other Possibilities for Language Classroom Interventions palestra proferida na Universidade de Emory, nos Estados Unidos em 2016. Disponível em: https://www.youtube.com/watch?v=211sWIN4kPY\&feature=youtu.be, acesso em 21/10/2016.
} 
desconstrução do que Kumaravadivelu (2012) classifica como a epistemologia do falante nativo e de todos os seus desdobramentos, tais como as noções de "proficiência nativa", "domínio de língua" e "competência nativa", por exemplo. Ora, se o uso que fazemos das diversas práticas discursivas a que temos acesso se relaciona intrinsecamente com a nossa relação e os nossos objetivos com o outro e/ou com o ambiente em questão, parece contraditório pensar que só é possível considerar um falante como sendo bilíngue caso ele atinja uma "proficiência nativa". Sendo assim, alinho-me a Salgado \& Dias (2010) ao entender que o indivíduo bilíngue é aquele "que pode utilizar, em algum nível, mais de uma língua" (2010, p. 2). García (2009) corrobora esse pensamento ao ponderar que

A crença em um bilinguismo balanceado contém a ideia de que o indivíduo bilíngue é uma espécie de duas pessoas, cada uma delas fluente em uma língua. De forma mais realística, o indivíduo bilíngue é aquele que "língua" diferentemente e que possui diversas e diferentes experiências com cada uma dessas línguas (GARCÍA, 2009, p. 45) .

A partir dessa mudança de foco, é possível aproximar a noção de bilinguismo da ideia de contato linguístico (SALGADO, 2008, p. 26). Salgado \& Dias (2010) argumentam que essa aproximação permite caracterizar o bilinguismo, também, como fenômeno sociopolítico, já que o relaciona ao "uso que um indivíduo faz dessas línguas" (SALGADO, 2008, p. 26), que por sua vez remete diretamente ao contexto no qual ele se insere. Assim sendo, o bilinguismo pode ser entendido como uma "situação em que coexistem mais de uma língua" (SALGADO \& DIAS, 2010, p. 2). Tais reflexões nos levam ainda a pensar que "devido à agentividade desse indivíduo que faz uso das línguas por ele apropriadas, podemos pensar em bilinguismo como instrumento de ideologia política e cultural, e não uma manifestação estritamente linguística" (2008, p. 26). Ou seja, ao fazer uso (ou não) de determinadas práticas discursivas, o indivíduo bilíngue se posiciona dentro do seu universo contextual, não só em termos linguísticos, mas também em termos ideológicos.

Dito isso, pode-se pensar que, muito mais do que fazer com que os aprendizes se tornem "proficientes" em uma língua, é necessário torna-los aptos a lançar mão de diferentes práticas discursivas nos mais variados contextos, a fim de agirem dentro de seus universos interacionais. É possível afirmar, então, que o objetivo da educação linguística deva ser o de fomentar o desenvolvimento de suas bilingualidades, sendo que a bilingualidade pode ser definida como "os diferentes estágios pelos quais os indivíduos bilíngues passam em sua trajetória de vida" (SALGADO \& DIAS, 2010, p. 4). É importante ressaltar, ainda, que uma vez que os indivíduos bilíngues possuem um repertório de práticas discursivas que é único, ainda que estejam inseridas em uma mesma situação de bilinguismo falantes em interação irão se expressar de forma singular e, por conseguinte, pode-se dizer que a bilingualidade de cada um é, também, única. Este é, também um conceito dinâmico, que se modifica em decorrência dos diferentes estágios, fases ou momentos de vida pelos quais o indivíduo bilíngue passa (SALGADO, 2008). A bilingualidade pode ter, assim, diferentes graus, dependendo em muito do contexto social no qual o aprendiz está inserido e do momento que ele está vivenciando.

O desenvolvimento de bilingualidade se faz imperativo na medida em que o processo de internetização (KUMARAVADIVELU, 2012) do mundo vem potencializando as oportunidades de contato linguístico através dos mais diversos suportes. É possível observar tal fenômeno através das mudanças na paisagem linguística ao nosso redor ou na própria

\footnotetext{
${ }^{4}$ Do original: "The belief in balanced bilingualism holds that a bilingual is like two persons, each fluent in one of the two languages. But more realistically, a bilingual is a person that "languages" differently and that has diverse and unequal experiences with each of the two languages" (GARCÍA, 2009, p. 45).
} 
criação de espaços subjetivos (MALINOVSKI, 2016) dos aprendizes, que influenciam diretamente na formação identitária dos falantes e, em se tratando de sala de aula, influenciam diretamente na maneira pela qual precisamos organizar este espaço.

Nessa perspectiva, García (2009) afirma que "a educação bilíngue é a única forma de educar crianças no século XXI” (2009, p.5). O termo educação bilíngue, porém, abrange diferentes concepções do que seja educar e assume diferentes orientações, que variam principalmente no que diz respeito a crenças e abordagens (GARCÍA, 2009). Para fomentar o desenvolvimento da bilingualidade dos aprendizes, acredito que uma proposta de educação bilíngue de caráter dinâmico - isto é, que desenvolva a capacidade de o aprendiz selecionar diferentes práticas comunicativas de acordo com o contexto no qual se inserem - com foco no aprendiz seja um bom caminho para alcançar tal objetivo. $\mathrm{O}$ foco no aprendiz promove o que chamarei a partir de agora de aprendizado incidental, que será discutido em detalhes a seguir.

Embora diferentes abordagens metodológicas possam se inserir dentro desta proposta, analiso aqui aulas que acontecem dentro da abordagem CLIL - Content and Language Integrated Learning. CLIL é um termo abrangente, usado para caracterizar "qualquer tipo de programa em que a língua é usada para ensinar conteúdos não linguísticos" (GARCÍA, 2009, p. 209). Pode-se dizer que tem foco duplo, uma vez que

\begin{abstract}
Alunos da abordagem CLIL não aprendem uma língua por simplesmente aprender ou para uso futuro, mas sim para colocar a língua recém aprendida em uso imediato, enquanto aprendem e manipulam conteúdos relevantes às suas vidas (MEHISTO et al, 2008, p. 21) .
\end{abstract}

O foco específico da abordagem no aprendizado e não no ensino promove a ocorrência de uma série de interações que, a piori, não haviam sido previstas pelo professor no momento de sua preparação de aula. Isso faz com que a abordagem CLIL acabe por ensejar o aprendizado incidental em uma escala maior do que outras abordagens o fariam.

As oportunidades de ocorrência de interações não planejadas dentro da sala de aula são importantes na medida em que, como pontua McWhinney (2005) ao propor seu modelo unificado para a aquisição de linguagem, "comparadas com adultos, crianças são relativamente mais influenciadas por sinais de disponibilidade do que por sinais de confiabilidade" $(2005, \text { p. } 53)^{6}$. Tal afirmativa sugere que crianças aprendem muito pelo que está disponível ao seu redor e, em se tratando de uma sala de aula, muito mais do que somente aquilo que é planejado pelo professor. A seleção do que será apreendido, porém, parece ocorrer de forma incidental, de acordo com os interesses e afinidades de cada aprendiz, que são variáveis.

É possível entender, assim, que durante a sua preparação de aula o professor tem em mente uma série de expectativas do que poderá ser apreendido por seus aprendizes. A este conjunto de expectativas, daremos o nome de aprendizado potencial, onde potencial se refere à projeção de práticas discursivas que o professor espera que seus alunos sejam capazes de assimilar. É possível notar, porém, que em contextos escolares envolvendo o aprendizado de crianças, o que é apreendido também ocorrem muito pela interação aprendiz-aprendiz e/ou aprendiz-ambiente. Nesses momentos, há um desvio de foco e a atenção da criança se volta

\footnotetext{
${ }^{5}$ Do original: "CLIL students are not learning a language simply for the sake of language learning and future use, but are putting just-learnt language into immediate use while learning and manipulating content that is relevant to their lives" (MEHISTO, 2008, p. 21).

6 “" [...] compared to adults, children are relatively more influenced by cue availability as opposed to cue reliability" (MacWHINNEY, 2005, p. 53).
} 
para essas interações e não para o tópico da aula. Dentro dessa perspectiva, o aprendizado não ocorre apenas pelo que é planejado ou projetado pelo professor, mas também a partir de interações diversas que envolvem outras relações que ultrapassam, mas não excluem, a professor-aluno. Chamo esse conjunto de apreensões não-programadas de aprendizado incidental.

Em linhas gerais, podemos entender o aprendizado incidental como sendo "o aprendizado não intencional ou não planejado que resulta de outra atividade" (KERKA, 2000, p. 1), no caso da sala de aula, a partir das interações não planejadas que não são o foco da aula no momento em que ocorrem. Vazquez et al (2014) ponderam que esse tipo "de processo de aprendizagem ocorre na ausência de consciência explícita do aprender e depende, mais diretamente, de fatores contextuais" (2014, p. 119) ${ }^{7}$. Dessa forma, quanto mais estímulos e oportunidades de interagir, maiores serão as chances de aprender. É importante ressaltar que a principal diferença entre o que classificamos aqui como aprendizado potencial e o aprendizado incidental é a questão focal. Enquanto o aprendizado potencial se dá em "situações de aprendizagem em que a criança e o professor focam sua atenção em torno dos mesmos objetivos de aprendizagem" (GRIM-FEINBERG, 2015, p. 9), o aprendizado incidental "pode envolver a atenção focal do aprendiz e/ou professor, que teriam objetivos diferentes" (GRIM-FEINBERG, 2015, p. 9).

\section{Metodologia}

O presente estudo se baseia em uma abordagem qualitativa. Podemos definir esse tipo de pesquisa como "um conjunto de atividades interpretativas [que] ${ }^{8}$ não privilegia nenhuma única prática metodológica em relação a outra" (DENZIN, 2006, p. 20). Sendo assim, trabalharemos com a interpretação de dados a fim de atribuir-lhes significados. Os dados em questão foram gerados a partir de duas pesquisas distintas. São elas: 1) Bilinguismo e educação infantil, desenvolvida entre 2009 e 2010 na Faculdade de Letras da Universidade Federal de Juiz de Fora e 2) Ensino de língua estrangeira para crianças, desenvolvido entre 2010 e 2011 em uma instituição particular de ensino de língua estrangeira na cidade de Juiz de Fora/MG. Estes dados estão disponíveis no banco de dados do GRUPELS - Grupo de Estudos em Linguagem e Sociedade -, na Universidade Federal de Juiz de Fora.

Foram estudadas as notas de campo, as notas expandidas e os vídeos produzidos a partir da observação participante de aulas e pela pesquisa-ação durante o período de duração dos dois projetos selecionados. Esta pesquisa qualitativa segue, então, o método de análise documental, na medida em que analisa os dados que foram produzidos por métodos etnográficos de pesquisa que ensejam "observações, durante certo período de tempo, por um grupo de pessoas associadas de alguma maneira, alguma unidade social representativa para estudo" (KAHLMEYER-MERTENS et al, 2007, p. 55). Sendo assim, não lançamos mão de análises ou medições estatísticas, mas antes privilegiaremos estudo de processos e significados, pois como bem define Denzin (2006), "os pesquisadores qualitativos ressaltam a natureza socialmente construída da realidade, a íntima relação entre pesquisador e o que é estudado e as limitações que influenciam a investigação" (2006, p. 23). Os dados coletados são analisados de forma indutiva, buscando melhor compreender como o aprendizado incidental de língua influenciou o desenvolvimento da bilingualidade e do letramento dos aprendizes naquele contexto, a fim de selecionar as informações necessárias para a discussão das questões apresentadas anteriormente.

\section{$O$ contexto escolar desta análise em questão}

\footnotetext{
${ }^{7}$ Do original: “[...] and it depends , more directly on contextual factors” (VAZQUEZ et al, 2014, P. 119)

${ }^{8}$ Acréscimo meu.
} 
A instituição particular de ensino de línguas estrangeiras que sediou uma das pesquisas citadas acima, cujos dados analisamos aqui se localiza na região central da cidade de Juiz de Fora/MG. Ela atende alunos de diferentes faixas etárias, começando com o ensino de línguas, pela abordagem CLIL, para crianças de 3 anos até o ensino para adultos. A instituição oferece cursos dentro da abordagem CLIL para crianças que tem entre 3 e 13 anos de idade. As séries conhecidas como $K$ compreendem crianças entre 3 e 5 anos e são os níveis $\mathrm{K} 1, \mathrm{~K} 2$ e K3. As séries conhecidas como $Y$ passam pelas turmas de Y1, Y2, Y3, P2, Y4 e Y5 e atende crianças que podem estar na faixa etária dos 6 aos 11 anos de idade. Por fim, existem as turmas que são classificadas como $S T$, que são cursos oferecidos a pré-adolescentes entre seus 11 e 13 anos de idade e que compreendem os níveis ST1, ST2, ST3 e ST4. Essa divisão curricular está representada na tabela abaixo:

\begin{tabular}{|c|c|c|}
\hline \multicolumn{3}{|c|}{ Organização curricular de acordo com níveis e turmas } \\
\hline Tipo de turma & Nível & Faixa etária média \\
\hline K & $\mathrm{K} 1$ & 3 anos \\
\hline $\mathbf{K}$ & $\mathrm{K} 2$ & 4 anos \\
\hline $\mathbf{K}$ & K3 & 5 anos \\
\hline $\mathbf{Y}$ & Y1 & 6 anos \\
\hline $\mathbf{Y}$ & Y2 & 7 anos \\
\hline $\mathbf{Y}$ & Y3 & 8 anos \\
\hline $\mathbf{Y}$ & $\mathrm{P} 2$ & $\begin{array}{l}9 \text { anos (alunos que chegam } \\
\text { novatos na escola nessa } \\
\text { idade) }\end{array}$ \\
\hline $\mathbf{Y}$ & Y4 & $\begin{array}{l}9 \text { anos (já estudam na escola } \\
\text { há pelo menos um ano) }\end{array}$ \\
\hline $\mathbf{Y}$ & Y5 & 10 anos \\
\hline ST & ST1 & $\begin{array}{l}11 \text { anos (alunos que chegam } \\
\text { novatos na escola nessa } \\
\text { idade) }\end{array}$ \\
\hline ST & ST2 & $\begin{array}{l}11 \text { a } 13 \text { anos (de acordo com } \\
\text { nivelamento feito no Y5) }\end{array}$ \\
\hline ST & ST3 & $\begin{array}{l}11 \text { a } 13 \text { anos (de acordo com } \\
\text { nivelamento feito no Y5) }\end{array}$ \\
\hline ST & ST4 & $\begin{array}{l}11 \text { a } 13 \text { anos (de acordo com } \\
\text { nivelamento feito no Y5) }\end{array}$ \\
\hline
\end{tabular}

Tabela 1: organização curricular da instituição de ensino pesquisada

Dentro deste estudo, consideraremos as observações feitas pelos pesquisadores no intervalo de turmas que compreende grupos $\mathrm{K} 1$ até $\mathrm{Y} 3$, por se encaixarem na faixa etária alvo da teoria na qual o trabalho se embasa. É importante ressaltar que, ao longo de dois anos, pesquisadores observaram aulas nessa instituição e produziram notas expandidas (ou NE) acerca de suas impressões sobre o ambiente, professores e produção dos alunos. Algumas produções dos alunos estão aqui analisadas a fim de ilustrar como se dá a interação aprendizaprendiz, aprendiz-contexto e aprendiz-professor (não planejada) e como ela contribui para o desenvolvimento de bilingualidade e letramento dos aprendizes ali inseridos.

\section{Análise de dados}


Os dados coletados foram analisados e agrupados em quatro categorias. São elas: 1) interações aprendiz-aprendiz; 2) interações aprendiz-contexto; 3) interações aprendizprofessor e 4) o desenvolvimento de letramento. Que são apresentadas a seguir com remissões teóricas.

\section{A interação aprendiz-aprendiz}

Como já foi dito anteriormente, a relação aprendiz-aprendiz se configura como uma importante ferramenta para o aprendizado de línguas entre as crianças. Talvez a principal questão envolvendo esse tipo de interação seja a autonomia que tais aprendizes desenvolvem ao interagirem entre si, precisando estabelecer regras para que sua comunicação ocorra e, com isso, tornando-se agentes no processo de construção de suas práticas discursivas. Acerca disso, Grim-Feinberg (2015) propõe que

No processo de 'ficar fora do caminho', as crianças brincam com irmãos primos e outros parentes jovens ou colegas de turmas, criando suas próprias formas de participação periférica sem diretivas dos adultos. Nessa estrutura de brincadeira, as crianças têm uma grande parcela de autonomia ao organizar suas próprias atividades, o que torna a situação rica para examinarmos como as crianças se apropriam das formas de comportamento e organização que acontecem ao seu redor enquanto elas brincam e aquelas que eles aprenderam por meio de suas famílias e atividades escolares (GRIM-FEINBERG, 2015, p. 1) ${ }^{9}$.

É possível entender, a partir do acima exposto, que no processo de interagir entre si, aprendizes se apropriam de práticas discursivas vivenciadas dentro e fora de sala de aula na tentativa de fazer sentido em suas relações dentro do contexto escolar e, assim, evitar a intervenção do professor. É possível observar abaixo alguns exemplos de interações desse tipo.

Situação 1: Os alunos estão fazendo uma aula de culinária (cooking class) quando, de repente, um aluno que até então não estava presente chega. Um dos colegas que já estava em sala diz:

'Hey, you, wash your hands and put your toquinha!' (W-NE12).

Situação 2: Em uma outra aula de culinária (cooking class) os alunos estão cortando alimentos para fazerem uma sopa quando a seguinte situação acontece:

'Rodrigo diz: 'Droga, eu cortei o meu dedo' e a Teacher Aline pede a ele: 'Hey, don't say that!', se referindo a ele ter dito a palavra 'droga'. O aluno Álvaro corrige e diz: 'Don't say like this, say: Shit, I cut my finger!' (J-NE08).

Situação 3: Em uma aula de matemática, os aprendizes entram em uma discussão sobre mobília de casa:

"Um menino perguntou como se dizia poltrona em inglês e o outro soltou: 'small sofa" "(W-NE30)

\footnotetext{
${ }^{9}$ Do original: "In the process of staying out of the way, children turn to play with siblings, cousins, and other young relatives or classmates, creating their own forms of peripheral participation without directives from adults. In the play frame, children have a great a deal of autonomy in organizing their own activities, which makes this a rich arena for examining how children appropriate the forms of behavior and organization that go on around them while they play, and those that they learned through family and school activities. (GRIM-FEINBERG, 2015, p. 1)
} 
Em todas as interações acima é possível entender essa apropriação linguística feita pelos alunos para muito além do que se pode chamar de code-switching. Quando escolhem utilizar a língua estrangeira em questão para interagir entre si, eles estão construindo um novo espaço simbólico de pertencimento e demarcando para si um novo local dentro daquele universo.

Além disso, é possível também observar uma rede colaborativa entre esses aprendizes, que se ajudam o tempo todo a selecionar os usos adequados a cada tipo de situação ou que os auxiliam na compreensão do que está sendo dito. Tal fenômeno pode ser caracterizado como scaffolding e é uma característica de aulas baseadas na abordagem CLIL. De acordo com Mehisto et al (2008), "em educação, scaffolding se relaciona a uma estrutura de suporte temporário que os aprendizes usam e confiam, com o objetivo de atingir resultados na aprendizagem" (2008, p.139). Em outras palavras, é um termo usado para se referir ao ato de trabalhar a noção de cooperação no processo de aprendizagem. Para Mehisto et al (2008), o scaffolding ocorre quando: 1) Constrói-se conhecimento a partir dos conhecimentos, habilidades, atitudes e experiências dos aprendizes; 2) Repensa-se a informação a fim de apresentá-la de forma mais adequada àquele grupo; 3) $\mathrm{O}$ planejamento de aula respeita diferentes estilos de aprendizagem; 4) Fomenta o pensamento crítico e criativo; 5) Desafia os aprendizes a avançarem nas suas habilidades, e não somente transitarem por uma zona de conforto (MEHISTO et al, p. 29).

Assim, embora se possa dizer que os aprendizes aprendem de forma subjetiva, o ambiente que os cerca e as interações das quais ele participa influenciam em muito o conhecimento que ele constrói e como ele potencializa suas oportunidades de apreensão ${ }^{10}$.

\section{A interação aprendiz-contexto}

Dentro da perspectiva interacionista para a aquisição de língua, o contexto desempenha um papel fundamental na construção de conhecimento do aprendiz. Nos exemplos selecionados abaixo, é possível visualizar o quanto os aprendizes se sentem seguros para se arriscarem a fazer piadas que se relacionam ao contexto na língua estrangeira em questão.

Situação 1: Os alunos acabaram de retornar à sala de aula após o almoço e começam seu processo de 'rotina', que é o momento em que se perguntam como estão, falam sobre a data e o tempo.

“Um dos alunos pergunta 'How have you been?' e o outro prontamente responde 'I am rice, thank you!' e sorri como quem sabe que acabou de fazer uma piada". (M-NE01).

\footnotetext{
${ }^{10}$ Ao interagir com o outro e com o ambiente que o cerca, o aprendiz se coloca em processo de negociação de sentidos para que, assim, ele possa agir discursivamente dentro daquele ambiente. Acerca desse processo de negociação, alinho-me ao que propõe Mehisto et al (2008) quando se diz que "Em educação, o termo 'negociação de sentidos' se refere ao processo no qual aprendizes e professores trabalham para transmitir informação, conhecimento e opiniões uns aos outros de forma a leva-los a um entendimento comum do que está sendo comunicado. Isso geralmente é feito por uma pessoa reformulando em suas próprias palavras o que a outra pessoa comunicou, esclarecendo as diferenças e confirmando fatos, opiniões, pensamentos, dentro outros" (2008, p.199). Acredito que esse processo impulsione o aprendiz no que diz respeito ao aprendizado de uma LE, na medida em que ele se torna capaz de compreender e produzir a partir do trabalho conjunto em níveis que não seria capaz, pelo menos por enquanto, de fazer sozinho.
} 
Situação 2: Em uma aula sobre matemática, a professora começa a escrever os números no quadro.

"A professora foi escrevendo os números de 1 a 20 no quadro e pedindo a eles que fossem lendo para ela.

A aluna Maria Clara diz: "Teacher, me coloca ai no 14 porque eu sou fortin", (JNE01)

Para além da graça, é possível observar que os alunos se apropriam de traços fonéticos da língua inglesa para darem um outro significado a palavras já existentes naquela língua. Ao fazer isso, eles acabam por quebrar expectativas em relação ao conteúdo programadas pelo professor - que, no caso, seria a matemática e a rotina inicial - a fim de ressignificar termos eenhecidos previamente. O que corrobora a ideia já apresentada por Mehisto et al (2008) sobre o desenvolvimento de autonomia e pensamento crítico do aprendiz dentro de contextos escolares baseados na abordagem CLIL

\section{A interação aprendiz-professor}

A interação entre aprendiz-professor não se restringe só a interações potenciais, já previstas no momento de preparação de uma aula. Elas podem se configurar, também, como situações de aprendizado incidental, justamente por fugirem do foco da aula naquele dado momento. O que as diferencia dos outros tipos de interação é o papel social representado pelo professor dentro do contexto escolar. É imprescindível ter em mente que o papel da escola é o de educar e mediar o processo de construção do conhecimento do aluno. Dessa forma, é responsabilidade do professor apresentar aos aprendizes ali inseridos ferramentas para que eles possam transitar linguisticamente entre os mais variados contextos: desde a interação com seus colegas de turma até a apresentação formal de um trabalho acadêmico, por exemplo. Esse processo, porém, não precisa delegar ao aluno um papel secundário. Muito pelo contrário: as novas demandas sugerem que os aprendizes precisam ter cada vez mais um papel central nesse processo, como já foi abordado anteriormente.

Míccoli (2011), já discute acerca da necessidade de operarmos uma mudança de foco como essa. Ela argumenta que as salas de aula em nosso país se pautam majoritariamente no que ela convencionou chamar de "metáfora do tubo". De acordo com a autora, essa visão delega ao aprendiz de LE um papel passivo no processo de aprendizagem, uma vez que sua "função " dentro do contexto escolar seria a de receber o conteúdo trabalhado pelo professor, passando pelas etapas de processamento do input linguístico e de uma possível negociação de sentido com o professor e outros aprendizes para, então, chegar ao momento de produção na LE em questão. A autora ainda aponta que tal abordagem pressupõe que o aprendiz desenvolva "uma competência gradual no uso da LE, passando por constante refinamento antes de alcançar a desejada proficiência - evidência da aquisição de língua" (2011, p.192 ).

Míccoli argumenta, então, que a partir de Vygotsky, a sala de aula passa a ser enxergada através do que ela classifica como a "a metáfora da participação", que postula que "a aprendizagem é processo que envolve estudante e professor numa meta comum: a participação da escola na comunidade de usuários que, no caso do ensino de LE, se constitui no espaço da sala de aula" (2011, p.196). Dentro dessa nova perspectiva, o professor passa a desempenhar um papel de facilitador do processo de aprendizagem, enquanto os alunos assumem a posição de agente ativo dentro desse processo, interagindo com o professor, o contexto e outros aprendizes no processo de construção do seu conhecimento.

Nos exemplos abaixo é possível entender como essas situações de aprendizado incidental entre aprendiz-professor se estabelecem 
Situação 1: Antes de a aula começar, o professor está brincando com um aluno com um quebra-cabeça.

"Sempre que os meninos chegam mais cedo o teacher Felipe dá-lhes um joguinho de quebra-cabeças de peças enormes para entretê-los até a hora da aula, com desenhos da Disney e do Bob Esponja. Foi interessante um momento em que, apontando para a água viva, Felipe disse: 'This is the jellyfish!', e Tales replicou: 'Não, esse não é o fish não, é a água-viva!!!'” (W-NE09).

A fim de lapidar esses conhecimentos incidentalmente adquiridos, Mehisto et al (2008) sugere que algumas técnicas podem ser aplicadas. O autor fala em uma hipótese de contrabalanceamento, defendida por Lyster \& Mori (2006). Para Mehisto et al (2006), "a hipótese de contrabalanceamento leva em consideração como os professores encorajam os aprendizes a aumentarem seus usos linguísticos precisos. Lyster \& Mori falam de recasts, correções explícitas e prompts" (MEHISTO et al, 2008, p. 169) ${ }^{11}$. A técnica de correção explícita informa ao aprendiz, de forma clara e direta, sobre seu desvio de uso. Já as outras técnicas são um pouco mais sutis. $\mathrm{O}$ recast consiste em reformular a enunciação para que o aprendiz possa reproduzi-la, a fim de entender qual a forma adequada a se usar naquele momento específico. Além disso, Mehisto et al (2008) pontuam que "recasts são ferramentas úteis de scaffolding quando os alunos ainda não têm a língua necessária para discutir conteúdos" (MEHISTO et al, 2008, p. 170) ${ }^{12}$. Já com prompt a abordagem é um pouco diferente, já que "o objetivo primário do prompt é fazer com que o aluno se auto-corrija" (MEHISTO et al, 2008, p. 170) ${ }^{13}$. Lyster \& Mori (2006) apontam que as duas técnicas podem ser usadas em conjunto, especialmente se levarmos em consideração que os aprendizes estão em processo constante de construção de seu conhecimento e podem ser capazes de se autocorrigirem em determinado grau, mas precisarem de auxílio em outros. Em suma, o professor deve lançar mão das técnicas que façam com que seus alunos se sintam o mais à vontade possível dentro de seu universo contextual em cada momento.

\section{4. $O$ desenvolvimento de letramento}

Como afirma Lombardi (2014) existem muitas possibilidades para se compreender e definir o que seja letramento. Parto do proposto por FREIRE (1991) e STREET (1984, 2003). Me concentro, porém, no estudo do letramento em língua estrangeira. Ainda segundo Lombardi (2014), ele

Se delineia [...] de maneira a incluir, no processo de ensino-aprendizagem, aspectos voltados para os contextos e usos reais, ou pelo menos potenciais, da língua, para além da simples decodificação do código linguístico. Ao invés de um ensino ancorado na transferência de habilidades de leitura, escrita, produção oral e escrita em língua materna para uma língua estrangeira, faz-se necessário levar em conta os possíveis meios com que os aprendizes podem utilizar a língua-alvo nas práticas sociais com as quais podem se defrontar na vida fora do ambiente escolar, sensibilizando-os, ainda, às diferenças culturais que subjazem tais práticas (LOMBARDI, 2014, pp. 48-49).

\footnotetext{
${ }^{11}$ Do original: The counterbalance hypothesis takes into account how teachers encourage students to increase accurate language usage. Lyster and Mori speak of recasts, explicit corrections and prompts" (MEHISTO et al, 2008, p. 169).

${ }^{12}$ Do original: "Recasts are helpful scaffolding tools when students lack the language needed to discuss content" (MEHISTO et al, 2008, p. 170)

${ }^{13}$ Do original: "The ultimate goal of the prompt is to support students self-repair" (MEHISTO et al, 2008, p. 170)
} 
É possível dizer que uma aula baseada na abordagem CLIL e potencializadora de aprendizado incidental promove também o letramento na medida em que, ao serem expostos a conteúdos em uma língua estrangeira, os aprendizes ali inseridos irão desenvolver vocabulário acadêmico, sua capacidade de se comunicar com o outro e fazer-se entender a partir da negociação de sentidos, ter contato e produzir diferentes tipos de textos, que fazem parte de sua realidade não somente escolar, como também cotidiana, eles tem foco no conteúdo e nos letramentos múltiplos dos alunos e a abordagem ainda prioriza o aprendizado multimodal de conceitos e conteúdos através da linguagem (CAMBRIDGE, 2015).

Situação 1: Os alunos têm uma aula em que visitam a casa de um dos colegas para descreverem os diferentes ambientes.

"No final da visita, ao agradecerem a mãe de Álvaro por te-los recebido, Lucas diz: "Very thank you'." (J-NE06)

O que vemos no exemplo acima, é o exercício de transliguação. A partir da situação descrita podemos ver que a criança-aprendiz está sendo agente de sua bilingualidade ao mesmo tempo em que está colocando em prática seu letramento social.

\section{Reflexões Finais}

É possível dizer que o aprendizado incidental fomenta o desenvolvimento da bilingualidade dos aprendizes na medida em que, ao se apropriar de determinadas práticas discursivas a fim de construir sentido em seus universos interacionais os aprendizes passam a discernir o que é cabível a cada contexto e passam a translinguar de acordo com as demandas sociais. Além disso, ele ultrapassa em muito o que é planejado pelo professor e é potencializado pela educação bilíngue, que possibilita o acesso a práticas discursivas através de estímulos multimodais ao disponibilizar no ambiente diferentes oportunidades e maneiras de aprender, contribuindo para o letramento dos aprendizes ali inseridos.

\section{Referências}

CAMBRIDGE ENSLIGH. Literacy in primary CLIL - supporting teacher in primary CLIL contexts. Webinar, 2015.

CANAGARAJAH, Suresh. Translanguaging in the Classroom: Emerging issues for research and pedagogy. Bloomsbury Review of Applied Linguistics \& Communication - 2010.

DENZIN, Norman K. \& LINCOLN, Yvonna S. A disciplina e a prática da pesquisa qualitativa. In: O Planejamento da Pesquisa qualitativa. Teorias e abordagnes. Trad. Sandra Regina Netz. Porto Alegre: Artmed, 2006, p. 15 - 41.

FREIRE, P. Pedagogia do oprimido. 4. ed. Rio de Janeiro: Paz e Terra, 1977.

GARCÍA, Ofélia. Bilingual Education in the $21^{\text {st }}$ Century: a global perspective. Wileyblackwell Publishing, 2009.

GRIM-FEINBERG, Kate. Understanding the Community through play: Incidental Learning in a Peruvian Agricultural Community. Paper presented at Anthropology of Children and Youth Interest Group Conference - March 13, 2015: California State University at Long Beach. 
JUFFERMANS, K. Local Languaging: Literacy Products and Practices in Gambian Society. Tese (Department of Culture Studies \& Babylon Centre). School of Humanities. Tilburg University. 2010.

KAHLMEYER-MERTENS, R et al. Como elaborar projetos de pesquisa: linguagem e método. Rio de Janeiro: FGV, 2007.

KERKA, Sandra. Incidental Learning: Trends and Issues alert. ERIC Clearinghouse on Adult, Career and Vocational education - Columbus, $\mathrm{n}^{\circ}$ 18, 2000.

KUMARAVEDIVELU, B. A Linguística Aplicada na era da globalização. In: Por uma Linguística Aplicada Indisciplinar. Ed. Parábola, 2006.

KUMARAVADIVELU, B. Individual Identity, Cultural globalization and Teaching English as na International Language - the case for na epistemic break. In: Identity and Globalization, 2012.

LYSTER, R.; MORI, H. Interactional feedback and instructional counterbalance. 2006.

MACWHINNEY, B. A unified model of language acquisition. In: KROLL, J. F. \& DE GROOT, A.M.B. Handbook of Bilingualism - Psycholinguistics Approach. Oxford University Press, 2005.

MEHISTO, P.; MARSH, D. \& FRIGOLS, M. J. Uncovering CLIL: Content and Language Integrated Learning in bilingual and multilingual education. Oxford, Inglaterra, Reino Unido: Macmillan Education, 2008.

MICCOLI, L. Ensino e Aprendizagem de Inglês: Experiências, Desafios e Possibilidades. Campinas: Pontes Editores, 2011)

SALGADO, Ana Cláudia Peters; DIAS, Fernanda Henrique. Desenvolver a bilingualidade: foco da educação bilíngue e do ensino de línguas. In: Revista Signo, v. 35 - 2010.

SHOHAMY, E. Language Policy: Hidden agendas and new approaches. Routldge, 2006.

STREET, B. Literacy in Theory and Practice. Cambridge: CUP, 1984. 256p.

VAZQUEZ, Ana Cláudia Souza; RUAS, Roberto Lima; CERVO, Clarissa S. \& HUTZ, Cláudio Simon. $\mathrm{Na}$ 'adventure' of MBA students in Europe: How volcanic ash produced na incidental learning experience. In: Academic Journals - vol. 9 (4), pp. 118-129-23 February 